\title{
Effect of the molecular weight of polycarbonate on the impact resistance of continuous carbon fiber reinforced polycarbonate composites
}

\author{
K. Tanaka ${ }^{1}$, H. Koriyama ${ }^{1}$, S. Isshiki ${ }^{1}$, T. Katayama ${ }^{1}$ \\ \& M. Shinohara ${ }^{2}$ \\ ${ }^{I}$ Department of Biomedical Engineering, Doshisha University, Japan \\ ${ }^{2}$ Department of Mechanical Engineering, \\ Maizuru National College of Technology, Japan
}

\begin{abstract}
In recent years, due to the increase in environmental issues, the production of fuel efficient cars has attracted attention. In order to obtain good gasoline mileage, reducing the weight of the car body is desirable. Carbon Fiber Reinforced Plastics (CFRP) have been attracting attention in the automotive industry for their light-weighted attributes. Thermoset plastics are mainly used as a matrix of CFRP in the automotive industry, although they cannot be melted or reformed after molding, and are difficult to recycle. On the other hand, since thermoplastic resin needs a shorter cycle time for molding and is recyclable, Carbon Fiber Reinforced Thermoplastics (CFRTP) are expected to be widely used in the automotive industry. Polycarbonate (PC) has high impact strength compared to other thermoplastic plastics, thus it is expected to be used as the matrix of CFRTP. The impact resistance of PC is dependent on its molecular weight and the impact resistance improves in proportion to the molecular weight. However, the impact resistance of $\mathrm{CF} / \mathrm{PC}$ due to differences in the molecular weight of PC is not well understood. In this study, the influence of the molecular weight of $\mathrm{PC}$ on the mechanical properties of $\mathrm{CF} / \mathrm{PC}$ composites is clarified.
\end{abstract}

Keywords: carbon fiber, polycarbonate, impact test, UD sheets. 


\section{Introduction}

Carbon Fiber Reinforced Plastics (CFRP) have advantages in high-specific strength and high-specific modulus, hence the demand for CFRP is increasing in aerospace, automotive and sports industries, etc. [1-4]. Especially the thermoset plastics like epoxy resins are mainly used as matrices of CFRP. Although the demand for CFRP is increasing in aerospace industry, their applications to the automobile industry are limited due to poor productivity and high cost. Furthermore, as the FRP using thermosetting resin cannot be remelted or reformed after molding, recycling is difficult. On the other hand, Carbon Fiber Reinforced Thermoplastics (CFRTP) are recyclable, good in productivity and excellent in impact strength, thus they are expected to be widely applied within the industry. As polycarbonate (PC) has high impact strength compared to other plastics, it is expected to be used as the matrix of CFRTP [5-8]. However, under the present circumstances, impact resistance of $\mathrm{CF} / \mathrm{PC}$ composites has not been obtained enough as is expected [8]. It is considered to be able to improve the impact resistance of CF/PC composites by using PC having a high molecular weight. Because impact resistance of $\mathrm{PC}$ is dependent on its molecular weight. However, high viscosity of PC makes it difficult to impregnate PC resin with carbon fiber and the impact resistance of $\mathrm{CF} / \mathrm{PC}$ due to differences in the molecular weight of PC is not well understood. In this study, the impact resistance of $\mathrm{CF} / \mathrm{PC}$ composites using a matrix of $\mathrm{PC}$ with low molecular weight and high molecular weight is evaluated by comparing with CF/PA composites.

\section{Materials and experimental procedures}

\subsection{Materials}

UD sheets of unidirectional carbon fiber reinforced composite(Teijin Ltd., Japan) (shown in Fig. 1) were used in this study. In order to clarify the influence of the molecular weight of $\mathrm{PC}$ on mechanical properties of $\mathrm{CF} / \mathrm{PC}$ composites, the matrix of PC with high-molecular weight (K-1300, molecular weight; 30,000) and low-molecular weight (AD-5503, molecular weight; 15,000) was

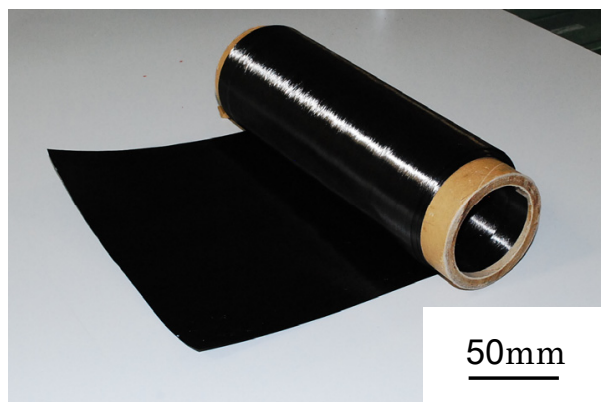

Figure 1: FUD sheet. 
used. In addition, PA (PA6) was used for the competitor to PC. The thickness, width and $V_{f}$ of UD sheets are $80 \mu \mathrm{m}, 110 \mathrm{~mm}$ and $54 \%$ respectively.

\subsection{Molding process}

Laminated composites of $\left[0^{\circ} / 90^{\circ}\right]_{13 s}$ were molded by a hot press forming machine into specimens of $2 \mathrm{~mm}$ in thickness. CF/PC were molded by heating at $300^{\circ} \mathrm{C}$ and maintained for 600 seconds; $\mathrm{CF} / \mathrm{PA}$ were molded at $270^{\circ} \mathrm{C}$ and maintained for 600 seconds. Cross sections of specimens were observed by scanning electron microscope (SEM, SEM-6390LT, JEOL Ltd., Japan) for evaluating resin impregnation.

\subsection{Drop weight impact test}

The drop weight impact tests were conducted by using the instrumented drop weight impact test machine (IITM-18, Yonekura Co., Japan) (shown in Fig. 2). The configuration of the specimen was a regular octagon shape, which had $25 \mathrm{~mm}$ in side length and $2 \mathrm{~mm}$ in thickness (shown in Fig. 3). A hemisphere of $10 \mathrm{~mm}$ in diameter was used as a striker. The height of drop weight (Mass of drop weight was $2.0 \mathrm{~kg}$ ) was adjusted so that imparted energy became $8 \mathrm{~J}$ per $1 \mathrm{~mm}$ in specimen thickness.

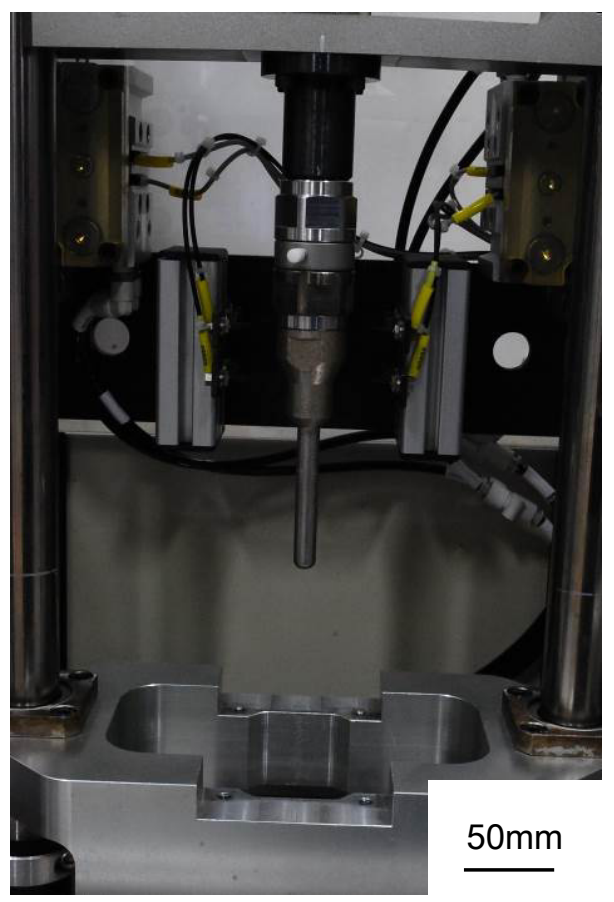

Figure 2: Drop weight impact test machine. 


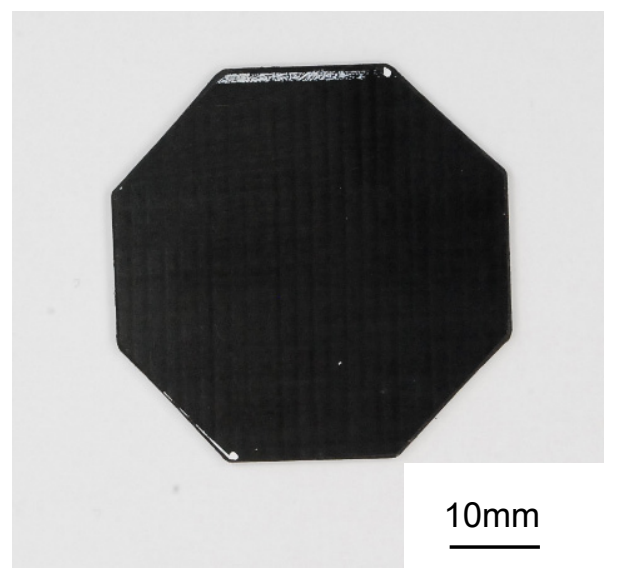

Figure 3: Specimen of drop weight impact test.

\section{Results and discussions}

\subsection{Evaluation of impregnation}

Cross sections of the molded specimens for K-1300, AD-5503 and PA6 are shown in Figs 4, 5 and 6 respectively. Void contents of K-1300, AD-5503 and PA6 were $0.80 \%, 0.79 \%$ and $0.87 \%$ respectively. Void content of any specimen was less than $1 \%$ and specimens with good quality were molded by using UD sheets.

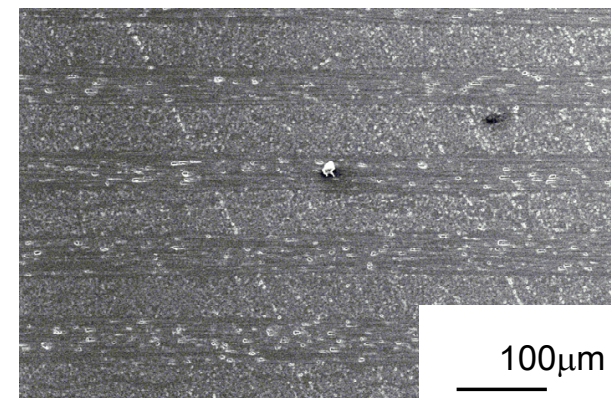

Figure 4: SEM image of the cross sections for CF/K-1300.

\subsection{Results of drop weight impact test}

Typical load-displacement curves for impact tests are shown in Fig. 7, and the absorbed energy-displacement curves are shown in Fig. 8. Table 1 shows the average values of maximum load and the average values of maximum absorbed energy. Average values of both maximum load and absorbed energy of PC were 


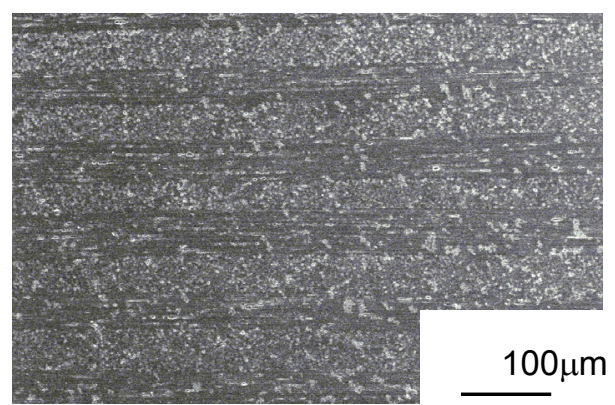

Figure 5: SEM image of the cross sections for CF/AD-5503.

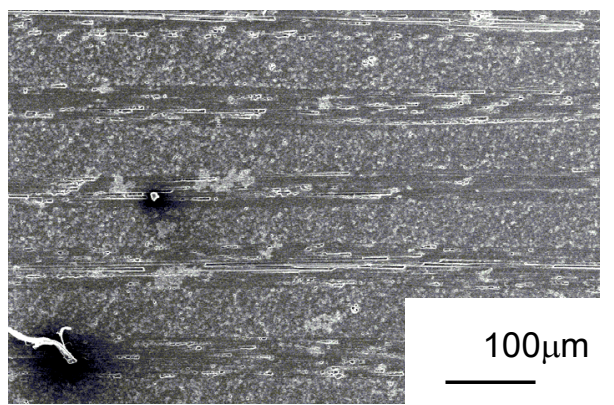

Figure 6: SEM image of the cross sections CF/PA6.

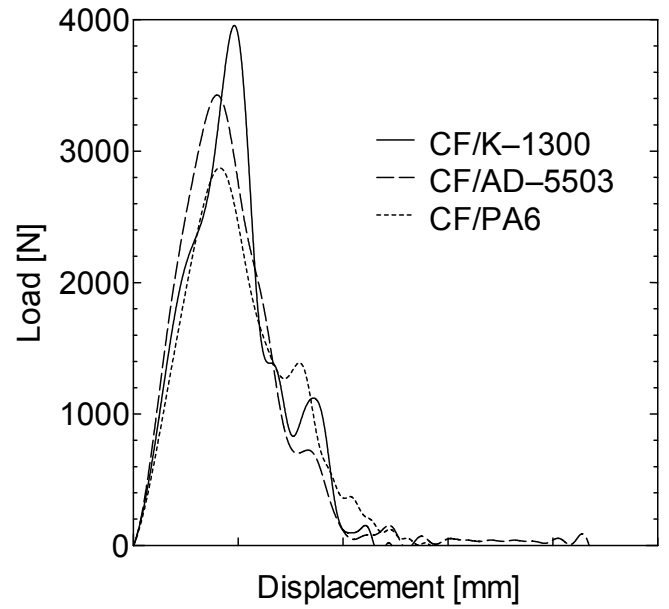

Figure 7: Load-displacement curve of drop weight impact test. 


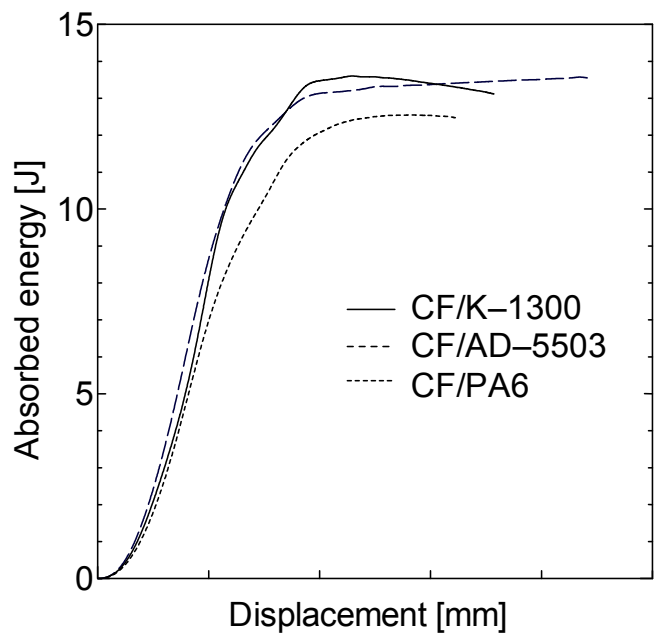

Figure 8: Absorbed energy-displacement curve of drop weight impact test.

Table 1: $\quad$ The maximum load and the maximum absorbed energy.

\begin{tabular}{|c|c|c|}
\hline & Maximum load $(\mathrm{kN})$ & Maximum absorbed energy $(\mathrm{kJ})$ \\
\hline $\mathrm{CF} / \mathrm{K}-1300$ & $3.94( \pm 0.09)$ & $14.1( \pm 0.7)$ \\
\hline $\mathrm{CF} / \mathrm{AD}-5503$ & $3.78( \pm 0.06)$ & $14.5( \pm 0.6)$ \\
\hline CF/PA6 & $3.21( \pm 0.11)$ & $12.1( \pm 0.9)$ \\
\hline
\end{tabular}

higher than those of PA. However the benefits of using PC for the purpose of improving impact resistance are smaller than that was expected by the impact resistance of neat resin. The average values of maximum load of high-molecular weight of PC were higher than those of low-molecular weight of PC. However, the average value of absorbed energy of high-molecular weight was as much as that of low-molecular weight. There is little effect on the impact resistance of $\mathrm{CF} / \mathrm{PC}$ composites by the difference in molecular weight of polycarbonate.

\section{Conclusion}

Influence of molecular weight on the drop weight impact test properties of $\mathrm{CF} / \mathrm{PC}$ composites was clarified. The investigation yielded the following conclusions:

(1) Laminated composites with good impregnation was molded by using UD sheets. 
(2) The impact resistance of $\mathrm{CF} / \mathrm{PC}$ was higher than that of $\mathrm{CF} / \mathrm{PA}$. However the benefits of using $\mathrm{PC}$ for the purpose of improving impact resistance are smaller than that was expected by the impact resistance of neat resin.

(3) There is little effect on the impact resistance of $\mathrm{CF} / \mathrm{PC}$ composites by the difference in molecular weight of polycarbonate.

\section{Acknowledgements}

This work was partially supported by a research project on "Research and Development Center for Advanced Composite Materials" of Doshisha University and MEXT (the Ministry of Education, Culture, Sports, Science and Technology, Japan) - Supported Program for the Strategic Research Foundation at Private Universities, 2013-2017, the project S1311036.

\section{References}

[1] S. Uotani, M, Yanagisawa, J. Itou, The composite material in such place. The CFRP in the mobile application, Present and future. Journal of the Japan Society for Composite Materials, 25(6), 236-239 (1999)

[2] A. Grant, Sporting composites, REINFORCED plastics, 49 (5), 46-49 (2005)

[3] A. Paesano, D. Cohee and G. R. Palmese, Carbon-fibre reinforced thermoplastic materials for rigidizable space systems, Journal of Thermoplastic Composite Material, 16(2), 139-170 (2003)

[4] T. Taki, K. Amaoka, Low-cost moulding technique of ACM for aircraft. III. Low-cost moulding technique of thermoplastic resin based composite materials and proposal on textile technology and research, Journal of the Japan Society for Composite Materials, 24(2), 41-48 (1998)

[5] S. Kida, M. Suzuki, K. Itoh, Instrumented charpy impact characteristics of polycarbonate; effects of notch length and temperature, The Japan Society of Mechanical Engineers, 57 (544), 3051-3056 (1991)

[6] S. Tahara, Polycarbonate, Journal of the Society of Rubber Science and technology, Japan, 43(3), 181-191 (1970)

[7] F. Nakao, S. Kume, H. Asai, Influence of molecular weight of matrix resin on mechanical properties of short carbon fiber reinforced polycarbonate, Journal of the Japan Society for Composite Materials, 18(6), 247-253 (1992)

[8] K. Tanaka, H. Kashihara, T. Katayama, Vacuum assisted high speed compression molding and evaluation of mechanical properties of continuous carbon fiber reinforced polycarbonate composite, Journal of the Society of Materials Science, Japan, 60(3), 251-258 (2011) 